\title{
MAKROZOOBENTOS SEBAGAI INDIKATOR BIOLOGIS DALAM MENENTUKAN KUALITAS AIR SUNGAI RANOYAPO, MINAHASA SELATAN, SULAWESI UTARA
}

\author{
Rifgah Marmita $^{1)}$, Ratna Siahaan $^{1)}$, Roni Koneri ${ }^{1)}$, Marnix L. Langoy ${ }^{1)}$ \\ ${ }^{1)}$ Program Studi Biologi FMIPA - Universitas Sam Ratulangi \\ J1. Kampus Unsrat, Manado 95115 \\ e-mail: unbett@yahoo.com; ratna245_siahaan@yahoo.com; \\ ronicaniago@yahoo.com; mlangoy@yahoo.com
}

\begin{abstract}
ABSTRAK
Sungai Ranoyapo merupakan sungai terpanjang di Wilayah Minahasa dengan panjang sekitar 60, $5 \mathrm{Km}$. Sungai Ranoyapo adalah sungai utama DAS Ranoyapo yang memiliki luas sekitar 87,154 Ha. Sungai Ranoyapo melintasi kawasan pertanian, perkebunan, permukiman penduduk, dan industri. Limbah yang berasal dari kawasan tersebut mempengaruhi kualitas air Sungai Ranoyapo. Makrozoobentos dapat digunakan sebagai parameter biologi dalam menentukan kondisi sungai karena hidupnya relatif diam di dasar sungai. Penelitian ini bertujuan untuk menentukan kualitas air Sungai Ranoyapo berdasarkan indeks keanekaragaman makrozoobentos. Penelitian dilakukan pada musim hujan yaitu Januari-Maret 2013. Lokasi penelitian ditentukan dari bagian hulu, tengah dan hilir sungai dengan 3 ulangan di tiap lokasi. Kualitas air Sungai Ranoyapo ditentukan berdasarkan indeks keanekaragaman makrozoobentos dari Shannon Wiener (H') menurut kriteria Staub et al (1970). Makrozoobentos di Sungai Ranoyapo terdiri dari 3 Filum, 5 Kelas, 13 Bangsa, 21 Suku, dan 23 Marga. Indeks keanekaragaman makrozoobentos dari Stasiun I (hulu), Stasiun II (tengah) dan Stasiun III (hilir) yaitu 2,43; 2,06; dan 1,77. Kualitas air Sungai Ranoyapo di Stasiun I dan di Stasiun II telah tercemar ringan dengan indeks $\mathrm{H}^{\prime}: 2,0-3,0\left(\mathrm{H}^{\prime}>2\right)$. Kualitas air Sungai Ranoyapo di Stasiun III telah tercemar sedang dengan indeks $\mathrm{H}^{\prime}$ sekitar 1,0-2,0 (H' $<2)$.
\end{abstract}

Kata kunci: Sungai Ranoyapo, kualitas air, pencemaran air, keanekaragaman makrozoobentos

\section{MACROZOOBENTHOS AS BIOINDICATOR IN DETERMINING WATER QUALITY OF RANOYAPO RIVER, SOUTH MINAHASA, NORTH SULAWESI}

\begin{abstract}
Ranoyapo River is the longest river in the Minahasa Region with its length of $60.5 \mathrm{Km}$. Ranoyapo River is the main river watershed Ranoyapo which its area of 87.154 ha. Ranoyapo River crosses agricultural, plantation, resident, and industry areas. Waste originated from those areas will affect water quality of Ranoyapo River. Macrozoobenthos can be used as a biological parameter in determining the condition of the river because they relatively slow move on the riverbed. This study aims to determine the water quality of the River Ranoyapo based on biodiversity index of macrozoobenthos. The study was conducted during the rainy season i.e. from January to March 2013. Three locations were chosen from upstream, midstream and downstream river with 3 replications in each location. The quality of Ranoyapo River was determined by the biodiversity index Shannon Wiener $\left(\mathrm{H}^{\prime}\right)$ of macrozoobenthos using classification of Staub et al (1970. Macrozoobenthos of Ranoyapo River consisted of 3 Phyla, 5 Classes, 13 Orders, 21 Families, and 23 Genus. Biodiversity index (H') of macrozoobenthos from up (Station I), middle (Station II) and downstream (Station III) respectively were 2.43; 2.06, and 1.77. The quality of Ranoyapo River at up and middle were lightly polluted with index H': 2.0 to $3.0\left(\mathrm{H}^{\prime}>2.0\right)$ and at down was moderately polluted with index $\mathrm{H}^{\prime}: 1.0$ to $2.0\left(\mathrm{H}^{\prime}<2\right)$.
\end{abstract}

Keywords: Ranoyapo River, water quality, water pollution, macrozoobenthos biodiversity 


\section{PENDAHULUAN}

Sungai Ranoyapo merupakan sungai terpanjang di wilayah Minahasa dengan panjang sekitar $60,5 \mathrm{Km}$. Sungai Ranoyapo merupakan sungai utama DAS Ranoyapo yang memilki luas sebesar 87.154 Ha. Sungai Ranoyapo rentan terhadap pencemaran. Hal ini disebabkan banyak aktivitas dari bagian hulu sampai ke hilir yang berpotensi menurunkan kualitas air sungai, misanya adanya kegiatan pertanian, perkebunan, permukiman, industri dan pertambangan. Penurunan kualitas air sungai akibat pencemaran berpengaruh negatif terhadap kehidupan biota perairan. Pencemaran air sungai juga dapat mengganggu kesehatan penduduk di sekitar DAS. Permasalahan kesehatan akibat air sungai yang tercemar dapat menyebabkan timbulnya berbagai penyakit seperti diare, disentri dan kolera (Suwondo, 2004). Bertitik tolak dari pemikiran tersebut, perlu dilakukan peneltian kualitas air Sungai Ranoyapo secara cepat dengan menggunakan makrozoobentos sebagai indikator biologis -kimia air untuk menentukan status kualitas di Sungai Ranoyapo. Penentuan tingkat kualitas Sungai Ranoyapo sangat diperlukan dalam upaya pengelolaan Sungai Ranoyapo bagi kesejahteraan penduduk dan keberlanjutan kehidupan biota baik yang hidup di dalam Sungai Ranoyapo maupun yang tergantung hidupnya pada Sungai Ranoyapo.

\section{METODOLOGI PENELITIAN}

\section{a. Tempat dan Waktu penelitian}

Penelitian dilaksanakan pada JanuariMaret 2013. Penelitian dilakukan pada 3 bagian Sungai Ranoyapo yaitu hulu, tengah dan hilir (Gambar 1) dengan 3 ulangan di tiap bagian sungai yang telah ditentukan. Hulu sungai berada di Desa Lindangan, Kecamatan Maesan. Tengah terletak di Desa Lompad Lama, Kecamatan Motoling. Desa Buyungon, Kecamatan Romoong Bawah dipilih mewakili bagian hilir Sungai Ranoyapo.

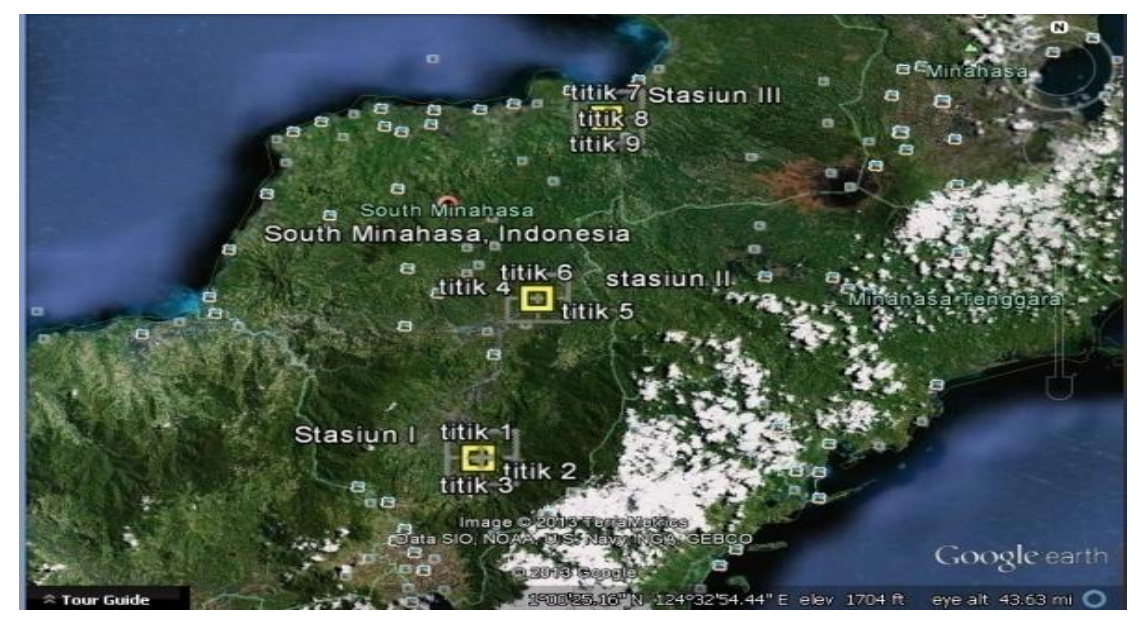

Sumber: Google Earth, 2013

Gambar 1. Lokasi penelitian

\section{b. Bahan dan Cara Kerja}

Pengambilan sampel makrozoobentos dilakukan menggunakan jaring surber $(25 \mathrm{x}$ 40) $\mathrm{cm}$, Pengambilan contoh makrozoobentos dilakukan dengan meletakkan jaring surber di dasar sungai. Posisi jaring surber diletakkan menghadap arah datangnya arus (Michael, 1994). Makrozoobentos diambil dengan cara mengeruk bagian luasan petak. Setelah proses pengambilan contoh makrozoobentos selesai, makrozoobentos segera disortir menggunakan saringan. Hasil sortiran segera dimasukan dalam botol sampel lalu diawetkan dengan alkohol 70\%. Makrozoobentos lalu di identifikasi menggunakan buku-buku indentifikasi (Seymour, 1992; Gui, 1994; Borror et al., 1996).

Kualitas air di Sungai Ranoyapo ditentukan berdasarkan indeks keanekaragaman makrozoobentos. Indeks 
keanekaragaman dihitung dengan menggunakan rumus Shannon-Wiener ( $\left.{ }^{\prime}\right)$ (Stiling, 1996). Kriteria Staub et al (1970) untuk tingkat pencemaran berdasarkan nilai indeks $\mathrm{H}^{\prime}$ yaitu tercemar sangat ringan $\left(\mathrm{H}^{\prime}\right.$ : $3,0-4,5)$, tercemar ringan ( $\left.H^{\prime}: 2,0-3,0\right)$, tercemar sedang $\left(\mathrm{H}^{\prime}: 1,0-2,0\right)$, dan tercemar berat (H': 0,0 - 1,0 ) (Wilhm, 1975; Siahaan, 2012). Kesamaan jenis makrozoobentos antar lokasi penelitian diperoleh dari indeks kesamaan jenis Sorensen (IS) (Odum,1996 dalam Istomo \& Kusmana, 1997)

\section{HASIL DAN PEMBAHASAN}

Makrozoobnetos yang ditemukan di Sungai Ranoyapo terdiri dari 3 Filum, 5 Kelas, 13 Bangsa, 21 Suku dan 23 Marga. Filum yang ditemukan yaitu Filum Arthropoda, Anelida dan Moluska. Filum Arthropoda merupakan makrozoobentos yang terbanyak ditemukan. Arthropoda yang ditemukan terdiri dari 2 Kelas, 8 Bangsa, 16 Suku dan 18 Marga. Filum Moluska merupakan taksa kedua yang paling banyak ditemukan yang terdiri dari 2 Kelas, 4 Bangsa, 4 Suku dan 4 Marga. Filum Annelida merupakan filum yang paling sedikit ditemukan di Sungai Ranoyapo yaitu Hirudo sp.

Jenis-jenis makrozoobentos di Stasiun I ada 18 jenis yaitu Mysis sp., Hemigrapsus sp., Pycnogonid sp., Hagenia sp., Habrophlebia sp., Dhubiraphia sp., Psepheneus sp., Cybister sp., Chimarra sp., Atherix sp., Simulium sp., Anthopotamus sp., Epeorus sp., Acroneuria sp., Pterornarcys sp., Rangovelia sp., Stenonema sp. dan Baetis sp. Jenis-jenis makrozoobentos di Stasiun II yaitu Pycnogonid sp., Cybister sp., Chimarra sp., Anthopotamus sp., Stenonema sp., Baetis sp., Acroneuria sp., Pterornarcys sp., Rhangovelia sp., Hagenia sp dan Hirudo sp. Jenis-jenis makrozoobentos di Stasiun III yaitu Mysis sp., Hemigrapsus sp., Psephenus sp., Hagenia sp., Melanoides sp., Theodoxus sp., Pomacea sp dan Sphaerium sp.

Keanekaragaman makrozoobentos menurun dari Stasiun I Ke Stasiun III (Gambar 2). Indeks H' makrozoobentos tertinggi pada Stasiun I (hulu) yakni 2,43. Indeks H' di Stasiun II (tengah) yaitu 2, 06. Indeks $\mathrm{H}^{\prime}$ terendah terdapat pada Stasiun III yakni 1,77. Keanekaragaman makrozoobentos pada setiap stasiun berkaitan juga dengan faktor lingkungan yang ada pada tiaptiap stasiun tersebut (Sastrawijaya, 2009). Indeks keanekaragaman yang tinggi di bagian hulu dan tengah ditunjang oleh faktor lingkungan yang sesuai dengan kondisi habitat untuk makrozoobentos dari Filum Arthropoda seperti kecepatan arus tinggi, penetrasi cahaya tembus hingga dasar sungai dan substrat dasar berbatu. Keanekaraman makrozoobentos dari Filum Arthropoda yang rendah di Stasiun III karena kecepatan arus yang lambat, air sungai yang keruh sehingga penetrasi cahaya tidak sampai dasar sungai, dan substrat berlumpur.

Kualitas air Sungai Ranoyapo dapat ditentukan berdasarkan indeks keanekaragaman makrozoobentos. Kualitas air Sungai Ranoyapo di Stasiun I (hulu) dan Stasiun II (tengah) dikategorikan telah tercemar ringan dengan indeks di lokasi tersebut sekitar 2,0-3,0. Sedangkan, kualitas air Sungai Ranoyapo di Stasiun III (hilir) telah tercemar sedang dengan indeks $\mathrm{H}^{\prime}$ sekitar $1,0-2,0$.

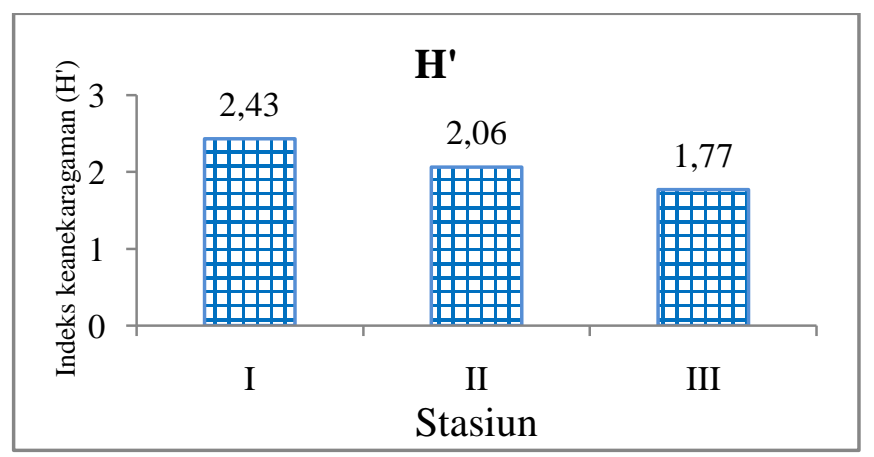

Gambar 2. Indeks Keanekaragaman Makrozoobentos dari Stasiun I ke Stasiun III 
Kelimpahan relatif taksa Ephemeroptera, Plecoptera dan Trichoptera menunjukkan penurunan dari hulu ke hilir (Gambar 3). Penurunan ketiga taksa ini dari hulu ke hilir diikuti dengan peningkatan taksa Moluska. Taksa Ephemeroptera. Plecoptera dan Trichoptera (EPT) adalah kelompok makrozoobentos yang peka terhadap pencemaran (Heliovaara \& Vaisanen, 1993). Kehadiran dan ketidakhadiran ketiga taksa ini dapat menunjukkan kualitas air sungai. Jika ketiga taksa ini hadir maka kualitas air sungai itu baik dan sebaliknya.

Makrozoobentos yang menjadi indikator biologis di Sungai Ranoyapo di
Stasiun I termasuk ke dalam Bangsa Ephemeroptera, Tricoptera, Plecoptera. Ketiga bangsa ini sebagai indikator biologis air sungai yang tergolong tidak tercemar sampai tercemar ringan. Makrozoobentos di Stasiun II termasuk ke dalam Bangsa Ephemeroptera, Hemiptera, Odonata dan Hirunidinida sebagai indikator biologis air sungai yang tergolong tercemar ringan sampai tercemar sedang. Makrozoobentos di Stasiun III termasuk ke dalam Kelas Crustacea (Bangsa Decapoda) dan Kelas Gastropoda sebagai indikator biologis air sungai yang tergolong tercemar sedang.

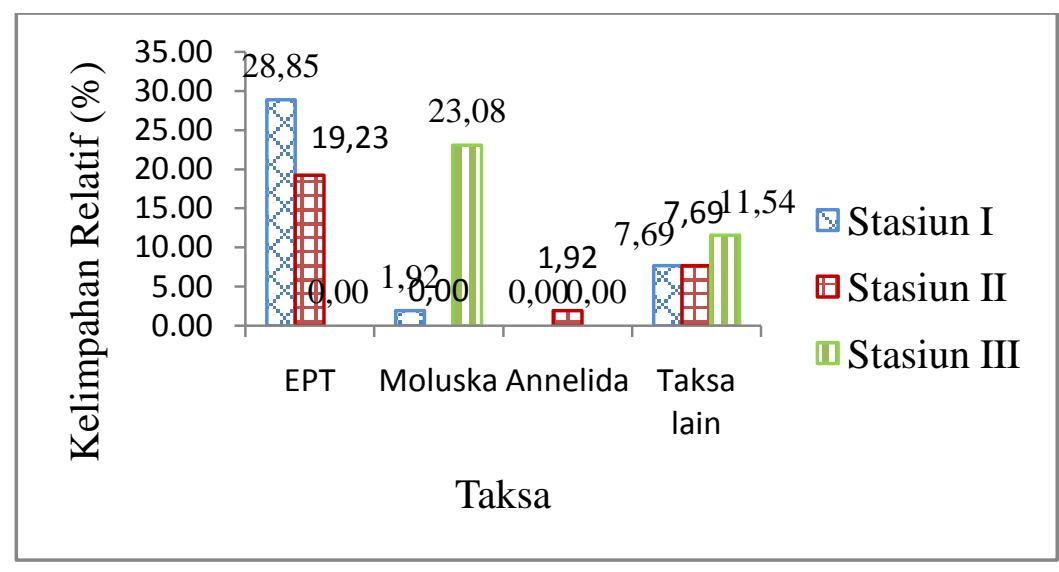

Keterangan: EPT: Ephemeroptera, Plecoptera, Trichoptera

Gambar 2. Komposisi Makrozoobentos dari Stasiun I ke Stasiun III

Komunitas makrozoobentos pada Stasiun I dan Stasiun II menunjukan kesamaan yang tinggi dengan nilai IS sebesar 0,52. Namun, Stasiun II dan Stasiun III memiliki indeks kesamaan yang rendah yakni 0,11 sehingga dapat dikatakan bahwa komunitas makrozoobentos di Stasiun I berbeda dengan di Stasiun II dan di Stasiun III. Komunitas makrozoobentos di Stasiun I dan Stasiun III berbeda dengan nilai IS sebesar $100 \%$. Hal ini menunjukkan bahwa tidak ada jenis makrozoobentos yang sama di Stasiun I dan Stasiun III.

\section{KESIMPULAN}

Makrozoobentos yang ditemukan di Sungai Ranoyapo terdiri dari 3 Filum, 5 Kelas, 13 Bangsa, 21 Suku, dan 23 Marga. Indeks keanekaragaman makrozoobentos dari Stasiun I (hulu), Stasiun II (tengah) dan Stasiun III (hilir) yaitu 2,43; 2,06; dan 1,77.
Kualitas air Sungai Ranoyapo di Stasiun I dan di Stasiun II telah tercemar ringan dengan indeks 2,0 - 3,0 ( $\left.\mathrm{H}^{\prime}>2\right)$. Kualitas air Sungai Ranoyapo di Stasiun III telah tercemar sedang dengan indeks H' sekitar 1,0 - 2,0 ( $\left.\mathrm{H}^{\prime}<2\right)$. Makrozoobentos yang dapat digunakan sebagai indikator biologis untuk pencemaran ringan yaitu Stenonema sp, Baetis sp (Ephemenoptera), Acroneuria sp, Pteronarcys sp (Plecoptera) di Stasiun I dan II, dan untuk pencemaran sedang yaitu Gastropoda di Stasiun III.

\section{Saran}

Penelitian ini dilakukan pada musim hujan sehingga untuk mendapatkan data kualitas air Sungai Ranoyapo yang lebih lengkap perlu dilakukan penelitian pada musim kemarau. Penelitian berulang pada tahun-tahun berikutnya juga perlu dilakukan mengingat kecendrungan peningkatan aktivitas manusia di DAS Ranoyapo. 


\section{DAFTAR PUSTAKA}

Borror, B.J.C., A.A. Triplehorn and N.F.Jhonson. 1996. Pengenalan Pelajaran Serangga. Edisi ke-6. Gajah Mada University Press, Yogyakarta.

Heliovaara, K. and R. Vaisanen. 1993. Insects and Pollution. CRC Press, Boca Raton.

Michael, P. 1994. Ekologi dan Penyelidikan Penelitian Lapangan dan Laboratorium. Universitas Indonesia, Jakarta.

Gui, H. 1984. Ephemeroptera. Di dalam: J.C. Morse, L. Yang and L. Tian (editor). Aquatic Insect of China Useful for Monitoring Water Quality. Hohai University Press, Nanjing.

Odum, E.P. 1996. Dasar-dasar Ekologi. Edisi Ketiga. Gajah Mada University Press, Yogyakarta.

Sastrawijaya, A.T. 2009. Pencemaran Lingkungan. Rineka Cipta, Surabaya.
Siahaan R. 2012. Keanekaragaman makrozoobentos sebagai indikator kualitas air Sungai Cisadane, Jawa Barat - Banten. J.Bioslogos. 2(1):p.19.

Stiling, P.D. 1996. Ecology: Theories and applications. $2^{\text {nd }}$ ed. Prentice Hall, London.

Seymour, R. L. 1992. Standard Methods For Examination Of Water And Waste. APHA, New York.

Suwondo, E. Febrita, A.M. Dessy. 2004. Kualitas Biologi Perairan Sungai Senapelan, Sago dan Sail di Kota Pekanbaru berdasarkan Bioindikator Plankton dan Bentos. Jurnal Biogenesis. 1(1):p.15-20.

Wilhm, J.L. 1975. Biological indicator of pollution. Di dalam: B.A.Whitton. Editor. River Ecology. Blackwell Scientific Publications, Oxford:p.375402.

Lampiran. Kelimpahan, Kekayaan dan Keanekaragaman Makrozoobentos di Sungai Ranoyapo

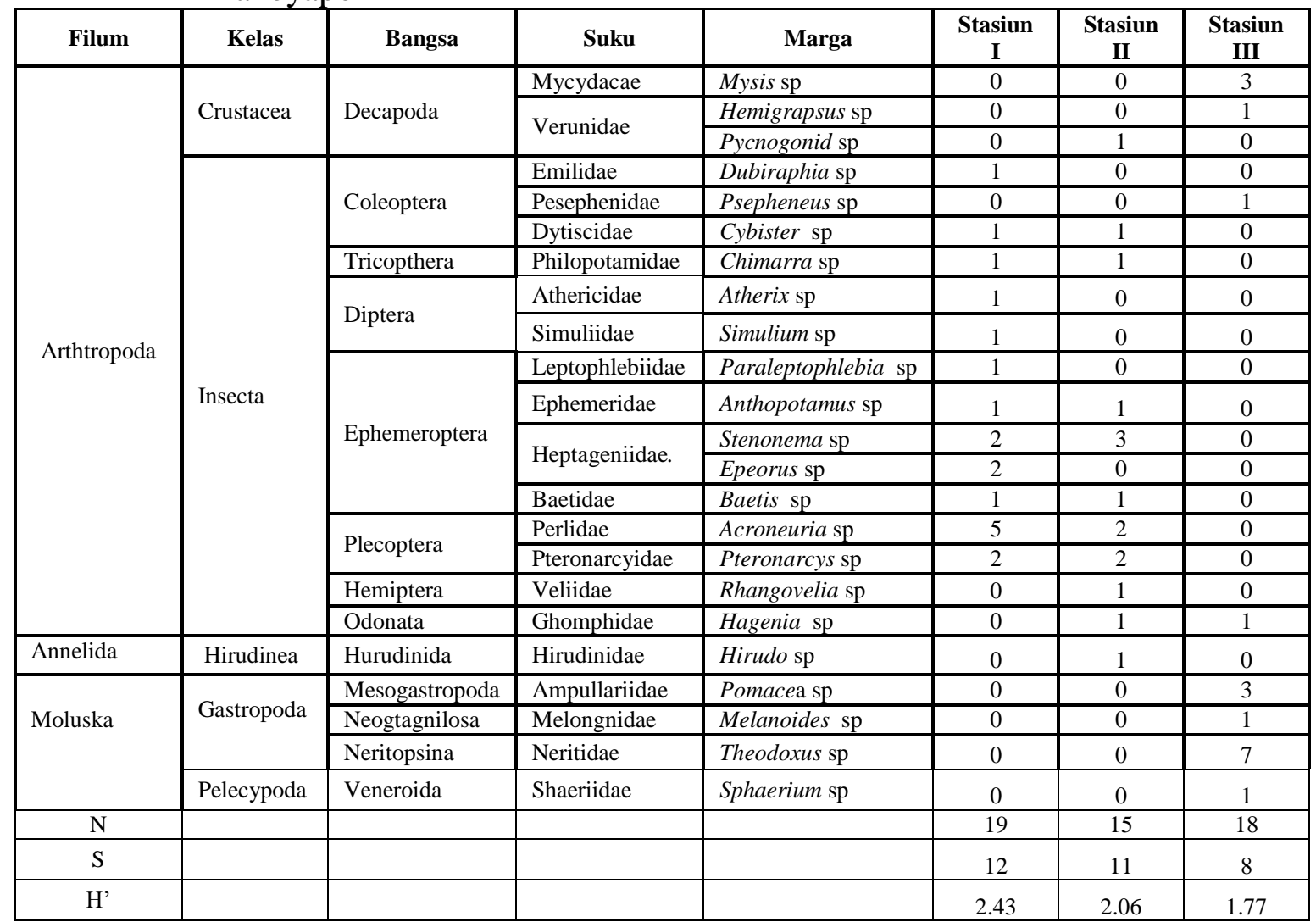

Keterangan:

N: kelimpahan; S: kekayaan jenis; H': indeks keanekaragaman 